\title{
Eco-geomorphic assessment of the Varanasi Turtle Sanctuary and its implication for Ganga River conservation
}

\author{
Gaurav Kailash Sonkar, Kumar Gaurav ${ }^{1, *}$, Niladri Dasgupt ${ }^{2}$, \\ Syed Ainul Hussain ${ }^{3}$ and Rajiv Sinha ${ }^{4}$ \\ ${ }^{1}$ Department of Earth and Environmental Sciences, Indian Institute of Science Education and Research, Bhopal 462 066, India \\ ${ }^{2}$ Ganga Aqualife Conservation Monitoring Centre, Wildlife Institute of India, Dehra Dun 248 001, India \\ ${ }^{3}$ Department of Landscape Level Planning and Management, Wildlife Institute of India, Dehra Dun 248 001, India \\ ${ }^{4}$ Department of Earth Sciences, Indian Institute of Technology, Kanpur 208 016, India
}

The eco-geomorphology of the Varanasi Turtle Sanctuary (VTS) located on the Ganga River in Uttar Pradesh, India was examined for its stability using hydraulic geometry of the channels, such as width, depth and discharge acquired from an Acoustic Doppler Current Profiler, and the mapping of planform morphology from remote-sensing images. Planform maps were generated using Corona and Landsat satellite images for the period 1965-2018. The assessment suggests a well-defined, stable cross-section profile along this stretch of the river. It provides conclusive evidence that the geomorphology of the Ganga River within the VTS has remained stable for the past 50 years, except for some minor changes in the form of bar growth and erosion both upstream and downstream of the sanctuary. Construction activities along the bank, movement of large vessels, sand mining in the sanctuary or dredging of the main channel may destabilize the river geomorphology that will negatively affect the integrity of the VTS as well as the ghats at Varanasi.

Keywords: Hydraulic geometry, planform morphology, river conservation, turtle sanctuary.

THE Ganga River near Varanasi, Uttar Pradesh, India, is an epitome of the constant conflict of humans with the natural environment. This stretch of the river has a prominent aquatic habitat, which supports many life forms, aquatic as well as terrestrial. The ghats on the left bank have a special religious and cultural significance for a large population of the country. However, the large human population and associated effluents are posing a serious threat to the aquatic health of the Ganga River ${ }^{1}$. To reduce pollution load in the river, softshell turtle species were introduced in the Ganga River at Varanasi in 1989, under Phase-1 of the Ganga Action Plan ${ }^{2}$. The softshell turtle (Nilssonia gangetica) feeds on human carcasses that are released into the river as a part of religious

\footnotetext{
*For correspondence. (e-mail: kgaurav@iiserb.ac.in)
}

ritual at the Manikarnika and Harishchandra ghats in Varanasi. They help in disintegrating large decaying organic matter. To ensure protection of these turtle species from poaching and other accidental human encounters, their habitat at Varanasi, a $7 \mathrm{~km}$ long stretch from Ramnagar to Malviya Bridge (Figure 1) was declared as the Varanasi Turtle Sanctuary (VTS) under the Wildlife (Protection) Act, 1972 (ref. 3).

As a part of the river conservation management measures and under the initiative by the Ganga Action Plan Phase I, the Kashi Forest Division started rearing N. gangetica at the Sarnath Turtle Centre and releasing them into VTS. The Sarnath Centre also acts as a rescue and rehabilitation facility for turtles confiscated from illegal trade and releasing them in the Sanctuary, enhancing the genetic diversity of the source population. Till today, the Kashi Forest Division has released more than about 41,000 turtles in to VTS. Apart from turtles, this stretch of the Ganga River is important for other conservationdependent species such as gharials (Gavialis gangeticus), dolphins (Platanista gangetica) and several island nesting birds $^{4,5}$.

Maintenance of flow and channel morphology as a conservation practice in this stretch of the Ganga is a huge challenge considering the geomorphic and ecological attributes, and societal significance of the stretch. When determining the morphological changes in a river, one must also consider the factors causing these changes and their consequences. Engineering structures such as dams, bridges and weirs may locally alter the morphology of alluvial rivers. They may also initiate aggradation or scouring of the channel bed ${ }^{6,7}$. As the ecological conditions and biotic associations in a river are significantly influenced by the geomorphic conditions of the river, any impact on the morphology of a river due to human intervention must be assessed.

Moreover, the ecological health of a river is a function of channel morphology and associated physical processes (e.g. discharge erosion and transportation of sediments). The temporal and spatial variability of channel processes 

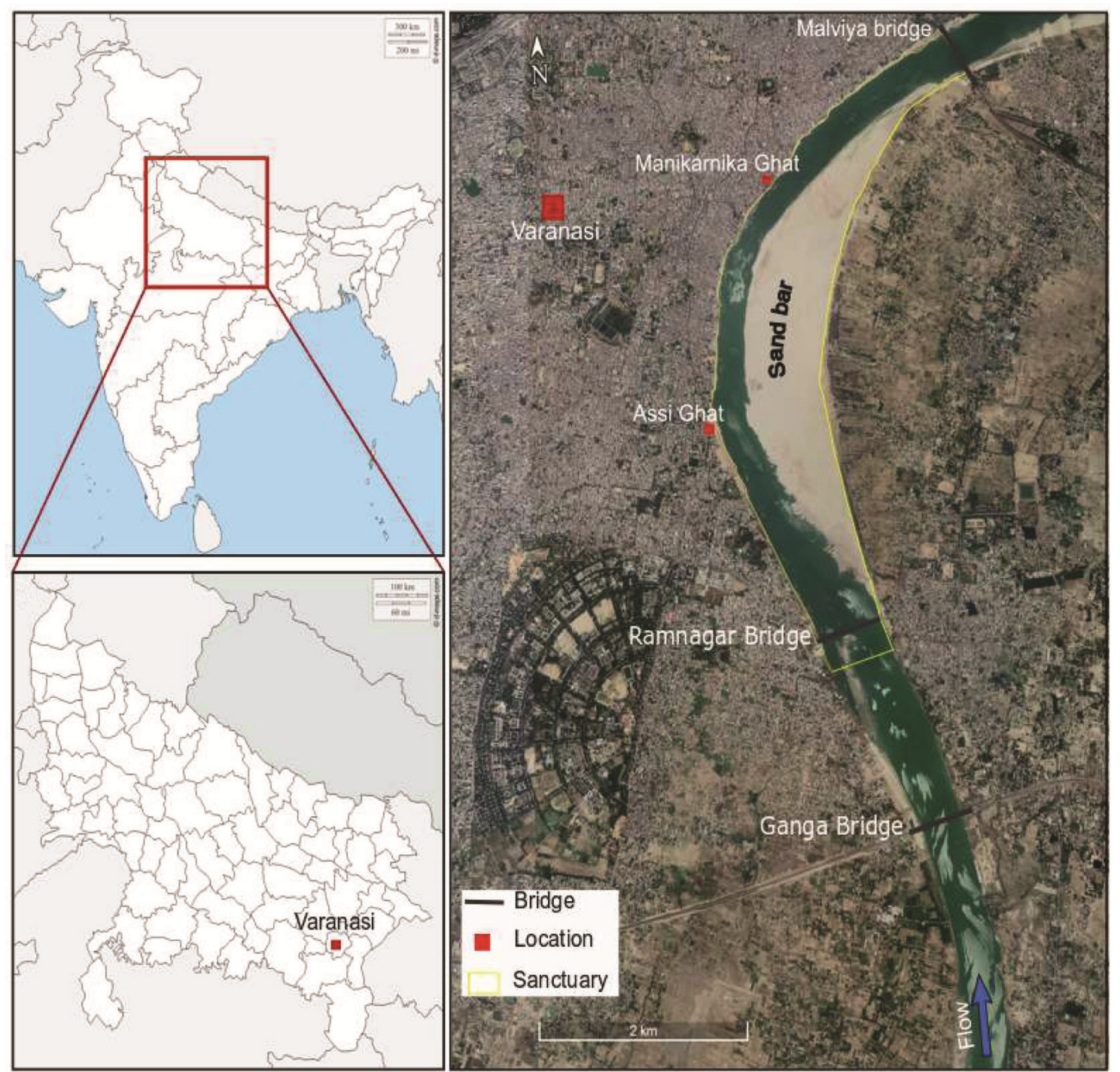

Figure 1. A planform view of the Ganga River and location of the Varanasi Turtle Sanctuary.

have particularly important controls on both local community composition and adaptive strategies for aquatic and riparian ecosystems ${ }^{8}$. Other important aspects include the distribution of different geomorphic units within the channel (e.g. islands, bars, pools and riffles) and the floodplains (e.g. flood basins, wetlands, active and inactive floodplains) that provide necessary habitat, and the longitudinal and lateral connectivity of a river?

Further, the proposed National Waterway-1 (NW-1) under the 'Jal Marg Vikas' Project (JMVP) is aimed at enabling the passage of cargo ships and boats through $\mathrm{VTS}^{10}$. This is expected to disrupt the morphological and ecological sanctity of VTS. In order to evaluate the impacts of these large-scale interventions, it is important to assess the scale of alteration(s) they may cause to the eco-geomorphic attributes of the river.

This study reports a preliminary analysis of the morphology and hydraulic parameters of the Ganga River at
VTS. Following this, we discuss how the passage of boats and cargo ships through the Sanctuary may affect the physical habitat by inducing changes in the channel morphology of the river.

\section{Ecological implications of river morphology}

Morphology of fluvial systems determines the habitat type and extent ${ }^{8}$. Temporal and longitudinal changes in the fluvial system bring about changes in the landscape ${ }^{8}$. The patches and corridors embedded in a landscape form the habitat in a fluvial system that varies at different scales (Figure 2). Microscale habitat pertains to cell level, habitat patch or a water column. Mesoscale habitat assessment is done at cross-section or reach scale, whereas macroscale assessment is carried out at the catchment scale ${ }^{11}$. The scale of interest on habitat study 


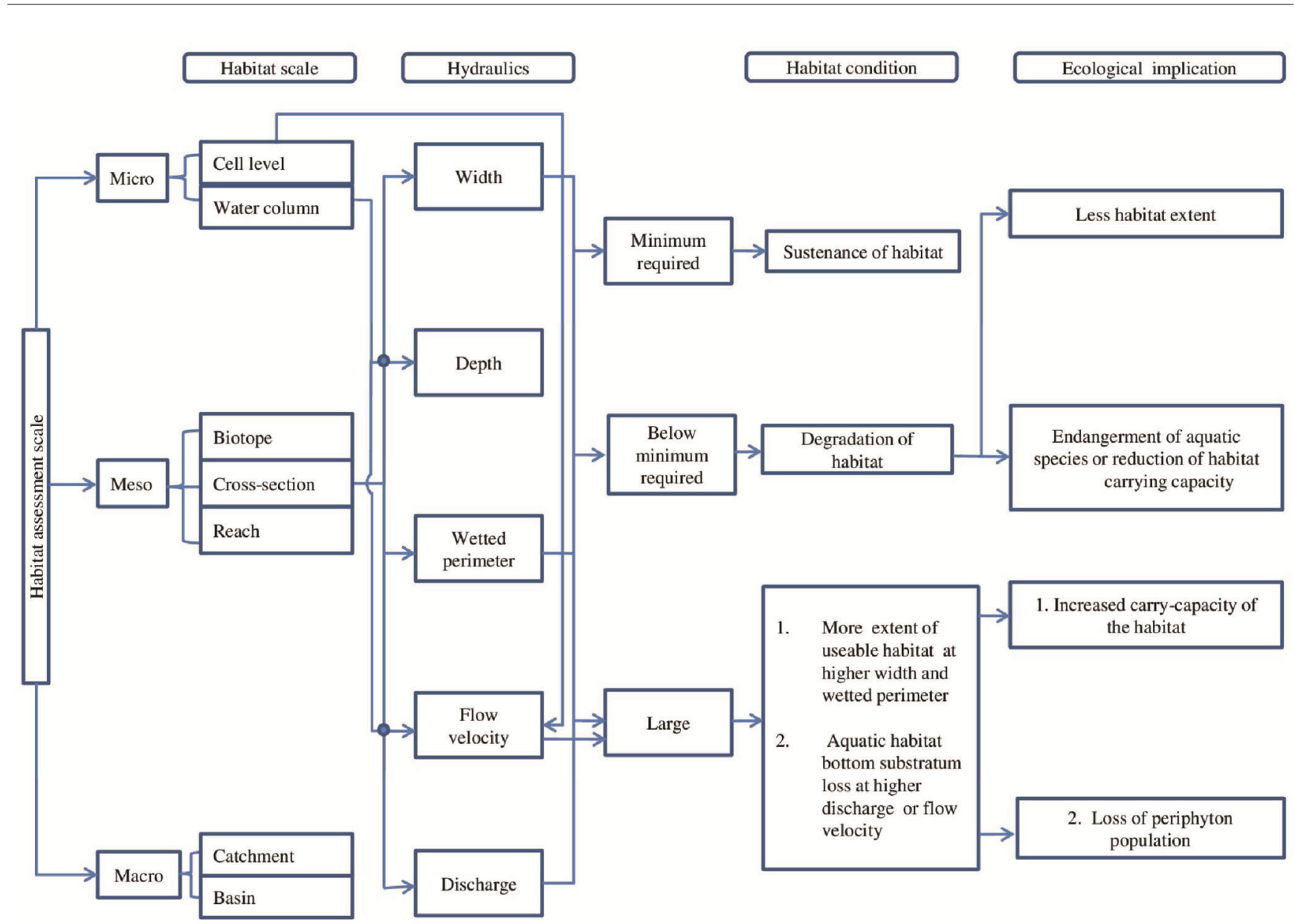

Figure 2. Conceptual overview of habitat assessment at different scales in a river.

depends on the objective and management strategy. The morphology-habitat relationship is usually studied at mesoscale.

Geomorphologic characteristics, such as geometry and planform, of mesoscale habitats are the basis of extent of physical habitat that is occupied by different biota. Any change in these characteristics may occur as a result of variations in water and sediment discharges of the river. It can lead to alteration or fragmentation of the existing habitat at a particular cross-section. For example, a reach of a river that receives high sediment flux usually aggrades the channel bed and forms a point or midchannel bar. Formation of point bar promotes encroachment and growth of riparian habitat ${ }^{12}$. In contrast, less sediment transport and high water discharge may lead to incision of a river channel.

A hydraulic assessment approach of a habitat links the physical environment with the biological distribution and behaviour. Quantification of the hydraulic properties of flow, such as width and wetted perimeter indicates the extent of river-channel biotopes. There is a certain level of protection provided by the channel width and wetted perimeter to the species inhabiting the river. If other spe- cies inhabit the same habitat, then maintaining minimum depth, width and sediment suspension becomes essential. A stream habitat may sustain different types of aquatic species; but, due to the functional role they play, their hydraulic requirement varies. To maintain the equilibrium between populations and energy flow in the community, each individual plays a specific functional role. This defines their niche along with their distribution. Another approach of river habitat assessment is species-specific hydraulic measurement. As established earlier, a minimum flow is required to sustain a suitable habitat, but this is a more generalized approach. High flow velocity and incised channel cross-section could ensure a suitable habitat for a particular species, but for others it might be lethal ${ }^{13}$. Habitat assessment with focus on single species and determination of its favourable hydraulic criteria simplifies the task. Such a species can be a 'target species' or a 'keystone species'. The habitat conservation of a target species can ensure the survival of other species in the community and maintain the integrity of the ecosystem.

From the purpose of conservation, turtles of VTS can be considered as the target species. A recent study 


\section{RESEARCH ARTICLES}

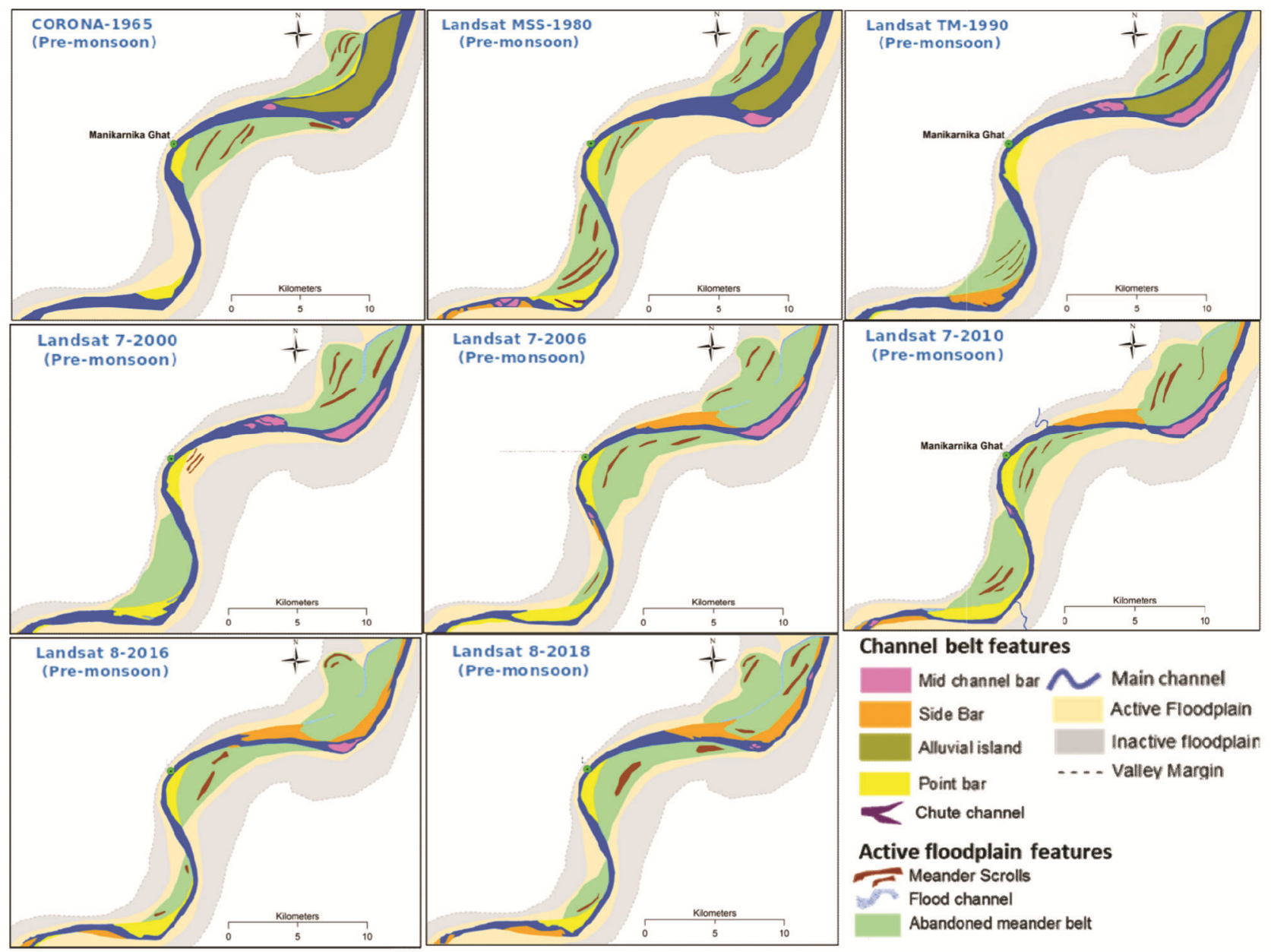

Figure 3. Time-series geomorphic mapping of the Ganga River at Varanasi using Corona (1965) and Landsat (1980-2018) images.

revealed the presence of five species of turtles from this stretch of the Ganga River. Different species of turtles have different patterns of resource use. Some species prefer shallow water and minimal flow velocity and basking. Other turtle species, due to their morphological advantages, occupy deep waters where flow velocity is comparatively higher ${ }^{14,15}$. Therefore, the focus should be on preserving the habitat of both shallow and deep water-inhabiting turtles. This will not only preserve the integrity of the river as a habitat, but will also provide continued protection to the other aquatic species sharing the same habitat in the Sanctuary. The present study uses the mesoscale approach to assess the geomorphic and hydraulic conditions of VTS.

\section{Methodology}

We have adopted two different approaches in this study planform mapping and hydraulic assessment. The former has been performed using the Corona (1965) and Landsat satellite time series images of the Ganga River at Varanasi
(Figure 3). First, a baseline morphology map was developed using the Corona image. Corona images were produced by a series of high spatial resolution $(2.75 \mathrm{~m})$ spy satellites that had operated from 1959 to 1972 . The Corona images helped us to reconstruct the planform morphology of the Ganga River that corresponds to the year before any major human intervention on the river. Temporal changes for subsequent years were mapped using the Landsat images from 1980 to 2018 pertaining to the premonsoon period (February-May).

In planform analysis, we studied and compared significant changes that have occurred in the different geomorphic units such as islands, bars, pools and riffles. For the assessment of hydraulic geometry (width, depth, velocity and discharge) of the river, we have used an Acoustic Doppler Current Profiler (ADCP) which works on the principle of Doppler effect; it emits high-frequency acoustic pulses and receives a proportion of the emitted energy that is reflected back by the suspended particles or bubbles. As the micro-particles move approximately at the velocity of water, the Doppler effect shifts the frequency of the reflected pulse. The magnitude of this shift 


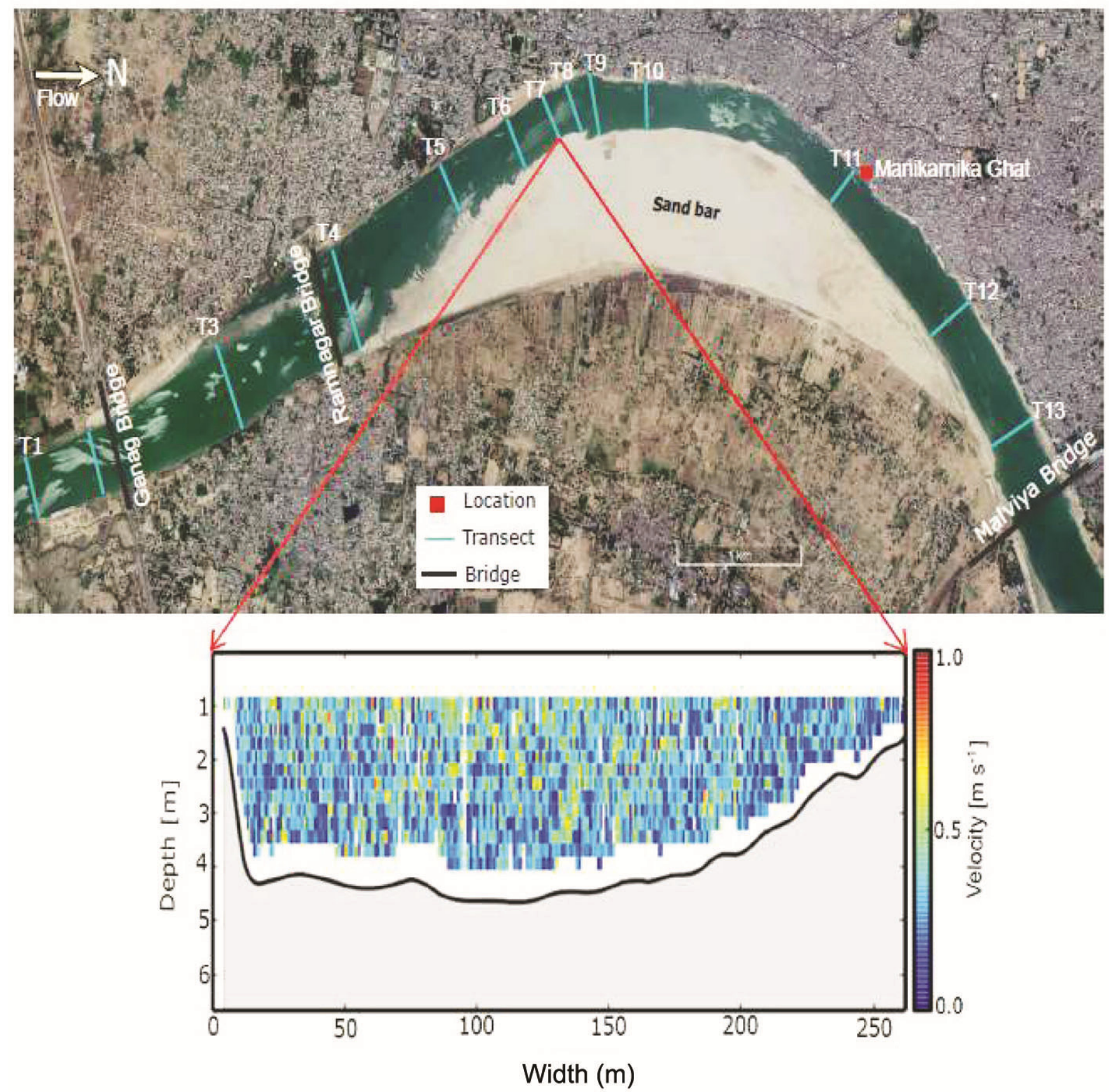

Figure 4. Velocity profile measured across the Ganga River channel at Manikarnika Ghat in Varanasi using ADCP.

is proportional to the water velocity projected along the direction of the acoustic beam ${ }^{16}$. To measure the mesohabitat parameter, we conducted a field campaign in February 2018, along the river near Varanasi and deployed an ADCP (Rio Grande $1200 \mathrm{kHz}$ ) on an inflatable motorboat platform. To record the location and improve the accuracy of channel depth, we supplemented the ADCP measurements with a handheld GPS and echo sound$\mathrm{er}^{17,18}$. The baud rate of the ADCP, echo sounder and GPS was set at $115,200,9,600$ and 4,600 bits/sec respec- tively. The channel was surveyed perpendicular to the flow direction to record channel depth, width and flow velocity at regular intervals across a given transect. Using these measurements, we calculated the flow discharge. In total, we have measured 13 cross-sections at different locations along VTS (Figure 4). At each location, we collected 2-3 consecutive transects. Using these repetitive measurements, we computed the relative error on the mean value as $10 \%, 15 \%, 5 \%$, and $12 \%$ for the channel width, depth, velocity and discharge respectively. 


\section{Results}

\section{Planform analysis}

Planform map for the year 1965 shows that a slightly wider channel existed in the past (Figure 3). The river primarily flowed in a single channel with little or no channel bars. Around Manikarnika Ghat, a prominent point bar (about $1.6 \mathrm{~km}^{2}$ ) and an abandoned meander belt existed on the opposite bank at the convex bend of the river (Figure 4). The active floodplain was narrow, and a large alluvial island (about $16.6 \mathrm{~km}^{2}$ ) was a prominent feature in the downstream end of this reach. In 1980, several meander scars are seen upstream of the Manikarnika Ghat could be seen, suggesting eastward shifting of the meander. The most prominent change during this period (1965-1980) was the strengthening of the northern anabranch of the channel in the most extreme downstream reach. However, this northern anabranch started to diminish by 1990 and disappeared by 2000. Another anabranch developed in the southern channel and a central bar started to grow since 1990. The large alluvial island nearly merged with the floodplain. Later in 2006, a prominent side bar developed immediately downstream of the Manikarnika Ghat, which exists till today. The large abandoned meander belt which developed opposite the Manikarnika Ghat is not a part of the active floodplain anymore. The small channel bar and anabranch in the extreme downstream reach have also disappeared, and are replaced by a side bar. Despite the physical changes, the overall morphology of the Ganga River at Varanasi has remained almost similar from 1965 to 2018, particularly the position of the major meander bend around the Manikarnika Ghat. However, significant changes in terms of channel dynamics, growth and erosion of channel bars and alluvial island have occurred both in the upstream and the downstream of the Manikarnika Ghat. The most obvious manifestation of this instability is the shifting of the meanders, although the main flow has been stable around the ghats.

\section{Hydraulics}

In accordance with the planform morphology, we observed well-defined channel cross-sections along VTS (Figure 4). Table 1 reports the measurement of width, depth, velocity and discharge across different transects (T1-T13). For comparison purposes, we have divided the Sanctuary into three different reaches - upstream (T1-T4), midstream (T5-T10) and downstream (T11-T13). There was significant increase in channel width (about 1.5 times) and decrease in channel depth (about half), as can be seen from T1 to T4 (Figure $5 a$ and $b$ ). A possible explanation of these changes could be the construction of the Ganga Bridge and Ramnagar Bridge that might have altered the flow and led to the deposition of sediments in the downstream reaches. This has further resulted in wider and shallower channel cross-sections. In the midstream transects (T5-T10), depth of the channel increases, whereas its width decreases gradually. The impact of the Ganga and Ramnagar bridges appears to reduce slowly in the midstream transects from T5 to T10, and the river approaches an equilibrium geometry. In the downstream transects from T11 to T13, there is an increase in both the channel width and depth. We also observed a sharp increase in channel depth at T13. It is important to notice that the Malviya Bridge is located at a distance of about $500 \mathrm{~m}$ downstream from T13. To the first order, it appears that this bridge alters the flow and initiates the scouring of the channels bed, resulting into channel incision.

To further assess the morphology of the Ganga River, we have plotted the aspect ratio as a function of distance (Figure $5 c$ ) from the upstream (Ganga Bridge) to the downstream (Malviya Bridge). Aspect ratio of a channel is a dimensionless quantity that allows distinguishing the meandering rivers from the braided pattern of rivers. Alluvial rivers found in nature often start to develop a braided pattern at aspect ratios of above 60 (refs 19, 20). In this study, we have considered an aspect ratio of 100 to analyse our cross-sections (Table 1). As expected, we found transects $\mathrm{T} 3, \mathrm{~T} 4$ and $\mathrm{T} 5$ exhibiting high aspect ratio of about 100, 196 and 136 respectively. This shows that the river is shallower and wider at these locations, and suggests that the initiation of channel bar may split the channel into more than one thread, leading to braiding. Further, the aspect ratio decreases in the downstream transects from T6 (98) to T13 (36), suggesting a single thread and relatively incised channels.

\section{Discussion}

Geomorphology provides a physical template for integrating ecosystem structure, function and alteration. The hydraulic measurements are useful in ascertaining the present river habitat conditions. A single channel with deep cross-sections provides natural protection from human predation. If we look at the depth profile of the entire Sanctuary, we can observe that the maximum depth is available in the upstream reaches. As we move downstream, depth decreases attaining a range between 3 and $4 \mathrm{~m}$. This indicates that VTS has adequate depth throughout its reach to support turtle habitat even during the low flow period.

Further, the upstream reaches of VTS have wider and shallower cross-sections indicating a relatively higher wetted area. In contrast, in the mid reaches of the Sanctuary the width of the channel decreases whereas the depth increases. In this reach, the river forms a meander with its convex bend along the left bank. This results in the deposition of sediments on the concave bend, forming a large 
RESEARCH ARTICLES

Table 1. Summary of the average depth, velocity and discharge computed from ADCP measurements at each transect

\begin{tabular}{|c|c|c|c|c|c|c|c|}
\hline Transect no. & Width (m) & Depth (m) & Discharge $\left(\mathrm{m}^{3} \mathrm{~s}^{-1}\right)$ & Velocity $\left(\mathrm{ms}^{-1}\right)$ & Aspect ratio & Latitude (dd) & Longitude (dd) \\
\hline $\mathrm{T} 1$ & 357 & 10.4 & 276 & 0.08 & 34 & 25.252 & 83.028 \\
\hline $\mathrm{T} 2$ & 392 & 8.7 & 291 & 0.08 & 45 & 25.254 & 83.028 \\
\hline $\mathrm{T} 3$ & 496 & 4.9 & 280 & 0.10 & 100 & 25.264 & 83.024 \\
\hline $\mathrm{T} 4$ & 637 & 3.2 & 262 & 0.17 & 196 & 25.273 & 83.019 \\
\hline $\mathrm{T} 5$ & 357 & 2.6 & 257 & 0.26 & 136 & 25.282 & 83.013 \\
\hline T6 & 309 & 3.1 & 265 & 0.26 & 98 & 25.285 & 83.011 \\
\hline T8 & 268 & 3.5 & 256 & 0.20 & 76 & 25.290 & 83.009 \\
\hline T9 & 320 & 3.5 & 236 & 0.19 & 90 & 25.291 & 83.008 \\
\hline $\mathrm{T} 10$ & 263 & 5.4 & 245 & 0.16 & 49 & 25.295 & 83.009 \\
\hline T11 & 262 & 5.4 & 235 & 0.15 & 48 & 25.309 & 83.015 \\
\hline $\mathrm{T} 12$ & 340 & 6.9 & 268 & 0.10 & 49 & 25.317 & 83.023 \\
\hline T13 & 335 & 9.3 & 289 & 0.08 & 36 & 25.321 & 83.030 \\
\hline
\end{tabular}
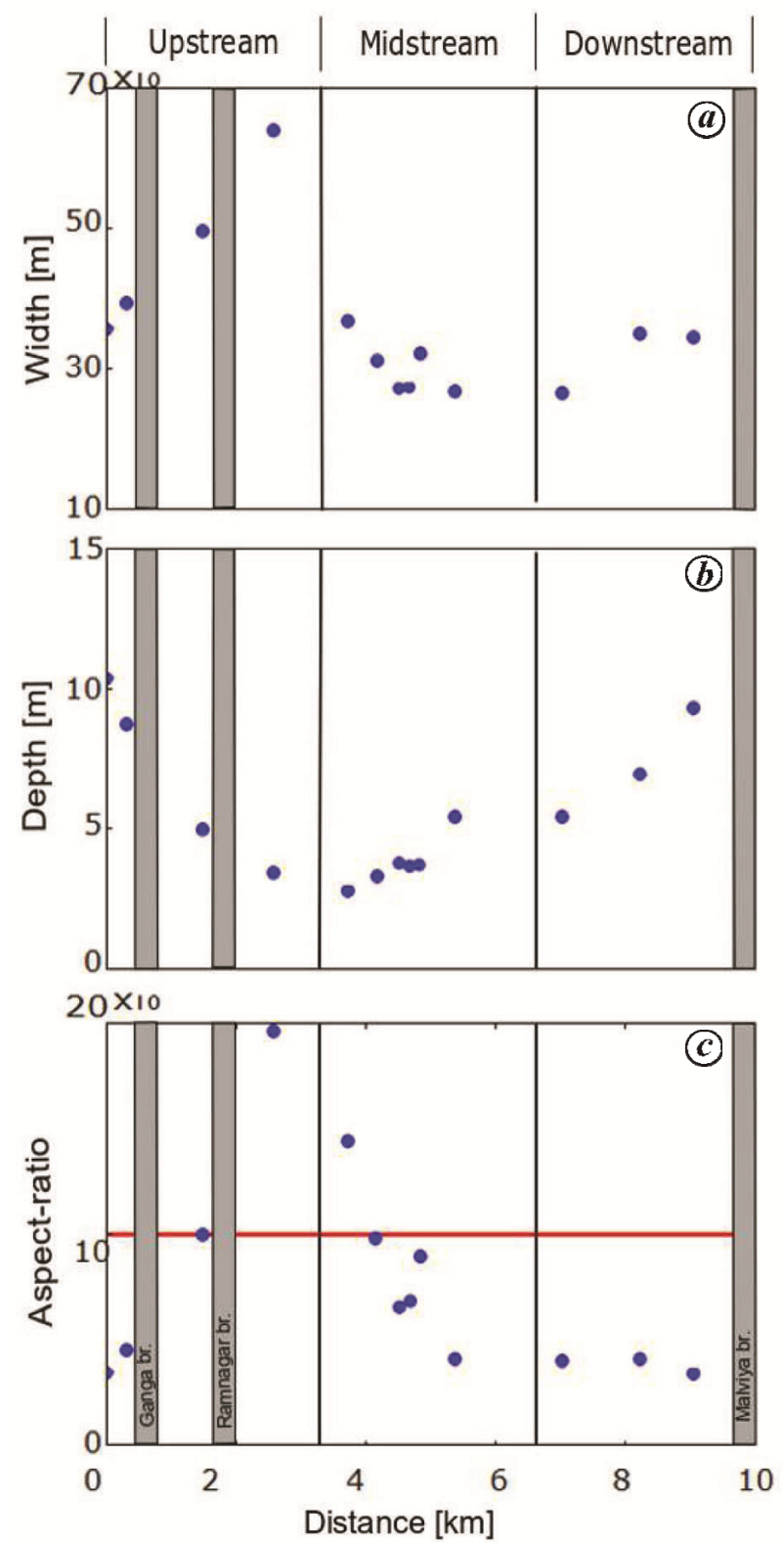

Figure 5. Variation in channel width, depth and aspect ratio of the Ganga River as a function of distance from upstream to downstream. point bar on the right bank of the river. Such locations are prone to human interactions, and therefore, are most unsuitable for turtles and other aquatic organisms to thrive. Morphological changes in the river resulting in the reduction of channel width and depth to their threshold values will eventually degrade the habitat.

Our investigation suggests that the morphology of the Ganga River in VTS has remained fairly stable during the past 50 years, except for some minor changes in the form of bar growth and erosion in the reaches upstream and downstream that are a little outside the Sanctuary limits. However, a major threat that can alter the morphology of the Ganga River to a great extent is from the proposed NW-1 system under JMVP that will enable the movement of large vessels into the river; this will run through VTS. This waterway has a planned route from Haldia to Allahabad across the Ganga, Bhagirathi and Hooghly rivers. The waterway scheme will allow the passage of cargo ships and boats through the Sanctuary ${ }^{21}$. These boats will generate large wavelength waves on the water surface that can exert lateral force on the banks. Such waves also have the tendency to travel far in comparison to waves with lesser wavelength. The amplitude and frequency of such waves increases and the wavelength decreases as they approach shallower depth. The waves would travel laterally and hit the banks and sometimes the channel bed; this may induce shear stress that can erode or resuspend sediments in the water column.

In several studies, the relationship between boat-generated waves and sediment resuspension concentration has been developed ${ }^{22-24}$. A boat travelling at a different speed at a different sailing length from the bank will produce a wave train which may cause suspension concentration to change $^{22}$. The most probable cause of sediment suspension from the channel bed is by the shear and lift force exerted by the movement of the boat/ship propeller. The lift force raises the sediment particles by turbulence and eddy currents, which eventually resettle. The resettlement rate depends on the particle size and concentration of the suspension. Turbidity drastically increases after passage 
of the boat, suggesting that boat traffic can easily surpass the natural factors responsible for turbidity and sediment suspension. Increase in ship traffic in the channel can increase bank erosion and sediment suspension of the Ganga River, and may hamper the existing suitable environmental conditions in VTS. The resuspended sediments are transported with discharge downstream or laterally towards the banks. This transportation of suspended sediments downstream can cause aggradation in certain reaches of the channel. We urge that it will disturb the morphological equilibrium that has been maintained in this region for long ${ }^{24}$. Varying deposition and erosion rate of channel bed can alter the river morphology. Shipinduced waves of high velocity/wavelength can uproot macrophytes, induce bank slumping and initiate habitat degradation. Apart from habitat degradation, resuspended sediments also reintroduce excess nutrients and toxicants into the water column, which may be remobilized and dissolved again. Since the entire Sanctuary in Varanasi is an ecologically sensitive and active habitat, a critical evaluation of factors that increase the rate of sediment suspension and transportation downstream is essential because of their potential to alter productive physical habitat.

\section{Conclusion and future directions}

Geomorphic mapping of the Ganga River at Varanasi from 1965 to 2018 shows that the reach has had a fairly stable planform morphology for the last $\sim 50$ years. The mapping was carried out using Corona images to construct planform for 1965, and Landsat MSS for 1997 and 1980, Landsat TM for 1990 and Landsat 7 and 8 for 2000-2018. It is evident that the reach of VTS from Ramnagar fort to Malviya Bridge has been maintained for the past 50 years, as there is no significant variation in the morphology of the Ganga River.

Channel cross-sections measured using ADCP in the field accord with the planform mapping. The channels are incised and stable at all transects with a relatively small variation in depth near the Ganga Bridge and Ramnagar Bridge. The velocity gradient of the channel crosssections shows almost similar profile throughout the study reach. Flow velocity is highest in the middle of the channel below the water surface and vanishes as it approaches the riverbed and laterally towards the bank. In terms of morphology, a reach downstream of the Sanctuary has been undergoing significant morphological changes. A large alluvial bar has merged with the floodplain on the northern bank. A stable morphology and hydrodynamics of the river channel provide a suitable habitat for turtles and other faunal species, and ensures their survival. As the Ganga is an alluvial river, it is susceptible to erosion. Any form of alteration in the existing physical habitat conditions, such as bank-side construc- tion activities, sand mining and dredging and large-scale river traffic may not only affect the channel stability but in turn will also cause irreparable damage to the Sanctuary as a habitat and also to the Varanasi ghats.

Although the scope of the present study is limited, our preliminary exploration and literature review suggest that there is ample scope to carry forward this research. There are several parameters that need to be taken into account and studied along with morphometric parameters to understand how the behaviours of turtles in the Sanctuary change with increasing human intervention and resulting habitat changes. A few of these may include the following:

(1) Assessment of the channel depth at temporal scale: It is important to record temporal variation in depth, if any, of zones where frequent sightings of a specific turtle species are recorded. This will provide a way to correlate and quantify the micro-habitat parameters for niche partitioning.

(2) Quantification of the bank erosion and increase in turbidity by the resuspension of sediments as a result of waves generated by boat movement at different depths and velocities is critical for assessment of the impact of the inland waterways project.

The banks with fine grain size are highly susceptible to erosion and resuspension, and this may affect the behaviour and mobility of the turtles in the river. Further, an increase in suspended sediment concentration due to resuspension and transportation downstream will not only decrease the light-penetration ability by increasing turbidity, and also mix the settled toxicants and contaminants in the channel bed. By documenting changes in the microhabitat parameters over time, we can infer the shift in microhabitat selection by the turtles and other aquatic fauna in VTS.

1. Kumar, S., Jha, P. and Baier, K., Pollution of Ganga River due to urbanization of Varanasi: Adverse conditions faced by the slum population. Environ. Urban ASIA, 2012, 3, 343-352.

2. MoEF, Annual Report 1989-90, Ministry of Environment and Forests, Government of India (GoI), 1990.

3. WII, Assessment of the wildlife values of the Ganga River from Bijnor to Ballia including turtle wildlife sanctuary, Wildlife Institute of India, Dehradun, 2018.

4. Behera, S., Areendran, G., Gautam, P. and Sagar, V., For a Living Ganga, 2011.

5. MoEF, India's Fifth National Report to the Convention on Biological Diversity, Ministry of Environment and Forests, GoI, 2014.

6. Gregory, K. J., The human role in changing river channels. Geomorphology, 2006, 79, 172-191.

7. Kondolf, G. M., Hungry water: effects of dams and gravel mining on river channels. Environ. Manage., 1997, 21, 533-551.

8. Thorp, J. H., Thoms, M. C. and Delong, M. D., The rivrine ecosystem synthesis: biocomplexity in river network across space and time. River Res. Appl., 2006, 22(2), 123-147. 
9. Junk, W. J., Bayley, P. B. and Sparks, R. E., The flood pulse concept in river - floodplain systems. In Canadian Special Publication of Fisheries and Aquatic Sciences, Canada, 1989, vol. 106, pp. $110-127$.

10. Ministry of Shipping, Cabinet approves Jal Marg Vikas Project for enhanced navigation on the Haldia-Varanasi stretch of National Waterway-1, Press Information Bureau, GoI, 2018.

11. Newson, M. D. and Newson, C. L., Geomorphology, ecology and river channel habitat: mesoscale approaches to basin-scale challenges. Prog. Phys. Geogr., 2000, 24, 195-217.

12. Corenblit, D., Tabacchi, E., Steiger, J. and Gurnell, A. M., Reciprocal interactions and adjustments between fluvial landforms and vegetation dynamics in river corridors: a review of complementary approaches. Earth-Sci. Rev., 2007, 84, 56-86.

13. Statzner, B., Gore, J. A. and Resh, V. H., Hydraulic stream ecology: observed patterns and potential applications. J. North Am. Benthol. Soc., 1988, 7(4), 307-360.

14. Jaeger, C. P. and Cobb, V. A., Comparative spatial ecologies of female painted turtles (Chrysemys picta) and red-eared sliders (Trachemys scripta) at Reelfoot Lake, Tennessee. Chelonian Conserv. Biol., 2012, 11, 59-67.

15. Lindeman, P. V., Resource use of five sympatric turtle species: effects of competition, phylogeny, and morphology. Can. J. Zool., 2000, 78,992-1008.

16. Chauvet, H. et al., Recirculation cells in a wide channel. Phys. Fluids, 2014, 26(1), 016604-10.

17. Gaurav, K. et al., Morphology of the Kosi megafan channels. Earth Surf. Dyn., 2015, 3(3), 321-331.

18. Gaurav, K., Tandon, S. K., Devauchelle, O., Sinha, R. and Métivier, F., A single width-discharge regime relationship for individual threads of braided and meandering rivers from the Himalayan Foreland. Geomorphology, 2017, 295, 126-133.
19. Fredsøe, J., Meandering and braiding of rivers. J. Fluid Mech., 1978, 84, 609-624.

20. Rosgen, D. L., A classification of natural rivers. Catena, 1994, 22, 169-199.

21. CUTS International, Expanding tradable benefits of inland waterways: case of India, 2017; www.cuts-international.org

22. Garrad, P. N. and Hey, R. D., Boat traffic, sediment resuspension and turbidity in a Broadland river. J. Hydrol., 1987, 95, 289-297.

23. Houser, C., Sediment resuspension by vessel-generated waves along the Savannah River, Georgia. J. Waterway. Port, Coastal, Ocean Eng., 2011, 137, 246-257.

24. Smart, M. M., Rada, R. G., Nielsen, D. N. and Claflin, T., The effect of commercial and recreational traffic on the resuspension of sediment in Navigation Pool 9 of the Upper Mississippi River. Hydrobiologia, 1985, 126, 263-274.

ACKNOWLEDGEMENTS. Funds for this study were provided by the Wildlife Institute of India, Dehra Dun through the grant WII/SAH/IITK-2018. K.G. thanks the Ministry of Earth Sciences, Government of India, for research funding (Letter no. MoES/ PAMC/H\&M/84/2016-PC-II). We thank IISER Bhopal and IIT Kanpur for providing institutional support. G.K.S. thanks the University Grants Commission, New Delhi for JRF fellowship to pursue Ph D at IISER Bhopal.

Received 29 January 2019; revised accepted 20 May 2019

doi: $10.18520 / \mathrm{cs} / \mathrm{v} 116 / \mathrm{i} 12 / 2063-2071$

\section{Erratum}

\section{Carbon storage potential of} mangroves - are we missing the boat?

\section{P. Ragavan, K. Sivakumar, R. S. C. Jayaraj, P. M. Mohan and T. S. Rana}

[Curr. Sci., 2019, 116(6), 889-891]

Page 890, 2nd column, para 2, line 9

The sentence should read as: They have estimated that the $\mathrm{CH}_{4}$ evasion rate $\left(96.5-1049.8 \mu \mathrm{mol} \mathrm{m}^{-2}\right.$ day $\left.^{-1}\right) \ldots$

\section{Instead of}

They have estimated that the $\mathrm{CH}_{4}$ evasion rate (96.5$\left.1049.8 \mathrm{mmol} \mathrm{m}^{-2} \mathrm{day}^{-1}\right) \ldots$.

We regret the error. 